IDEAs IN EcRlogy AND EVRLutian 5: 6-8, 2012

doi:10.4033/iee.2012.5.2.c

(C) 2012 The Author. (C) Ideas in Ecology and Evolution 2012

Received 31 January 2012; Accepted 10 February 2012

Commentary

\title{
Compound leaves and the evolution of leaf size and display
}

\author{
Rubén Milla \\ Rubén Milla (ruben.milla@gmail.com), Área de Biodiversidad y Conservación, Universidad Rey Juan Carlos, c/ \\ Tulipán s/n., E-28933 Móstoles (Madrid), Spain
}

Botanists would agree that the diversity of leaves does not lie in their physiological variation, which is comparatively modest, but in the overwhelming variety of morphological ways that the plants have evolved to display units of light-capturing surface (Bell 1991). Yet, our understanding of the adaptive value of functionalphysiological variation is much more advanced than that of morphological diversity. Try performing a Google Scholar search aiming to retrieve the number of empirical papers published during the last decade on the ecology of traits such as specific leaf area, leaf longevity, rates of gas exchange, or nutrient contents of leaves. You will need some free space in your hard disk to download all of them. Then try to gather the literature, for the same time span, focused on quantitatively unraveling the adaptive value of traits such as leaf margin patterning, petiole-to-lamina mass ratios, phyllotaxy, heterophylly, or the degree of leaf dissection. You will be done much faster. The progress in understanding the extent and ecological meaning of variation in economic leaf traits has been one of the most fruitful moves ahead in plant ecology. Yet, we have left aside morphological leaf traits with promising aptitudes to help understand plant evolution and adaptation.

It is then stimulating to read Lonnie Aarssen's paper, proposing a fresh new idea on the adaptive (...or perhaps lack of) value of the compound leaf (Aarssen 2012). Aarssen argues that compound leaves probably evolved as a means to reduce total leaf lamina size. Why should a plant be interested in reducing lamina size? Because leaf size correlates negatively with the amount of leaves built per unit of shoot mass or volume (i.e. with leafing intensity). Leafing intensity is argued to provide a number of adaptive advantages, chiefly related to the developmental plasticity that bearing a high number of axillary meristem provides (Kleiman and Aarssen 2007). Therefore, the evolution of compound leaves is proposed to be a mechanism to increase leafing intensity. Aarssen's idea is thus an extension of the leafing intensity premium hypothesis.

This is a nice and valuable suggestion on a most interesting issue, so let's examine it critically. First, let's think on the assumptions upon which this new hypothesis lies. A fundamental assumption is that compound leaves have evolved parallel to a decrease in leaf sizes (Figure 1 in Aarssen 2012). Is this a tenable assumption? Compoundness is a derived trait in angiosperms, independently evolved in several linages from simple leaves (Cronquist 1988). There are two ways to move from a simple to a compound leaf. The traditional view is that the compound leaf is an extreme secondary dissection of a simple template (Kaplan 2001). Under this view, entire, lobed, dissected, and compound leaves are grades along a continuum. Alternatively, compound leaves may arise as simple leaves reiterated as leaflets attached to a common new kind of "petiole"-i.e., the rachis (Champagne and Sinha 2004). The first view implies leaf lamina reduction while the second view does not. Current molecular evidence says that compound leaves are not dissections of simple leaves, but iterations of simple leaf lamina pieces (Efroni et al. 2010). Overexpression of regulatory genes involved in compoundness (e.g. uni, afilia, and tendrilless in pea) make leaflets produce additional leaflets as reiterations, not increasing the degree of lamina dissection (Champagne et al. 2007, Efroni et al. 2010). Therefore, we may say that Aarssen's (2012) assumption that the size of compound leaves is smaller than that of their simpleleaved ancestors requires formal testing (e.g. a phylogenetically-controlled comparative survey). 
Another assumption of Aarssen (2012) is the leafing intensity premium hypothesis itself. The validity of this proposition lies behind Aarssen's idea that the evolution of compound leaves is meant to increase the intensity of leaf display. The leafing intensity premium hypothesis states that the empirical negative correlation between leaf size and number can be directly used to infer that leafing intensity, and not leaf size, has been the trait under intense selective pressures during plant evolution. Arguments favouring this view are well-argued and plausible, but still verbal (see Kleiman and Aarssen 2007 or Whitman and Aarssen 2010). This was analysed by Milla (2009), and Whitman and Aarssen (2010), who found that small leaf sizes and loose leafing intensities were both more abundant in nature than large leaves and intensely leaved shoots. Although this is mathematically compatible with the negative isometric relationship between leaf size and leafing intensity (see Milla 2009, Whitman and Aarssen 2010), it casts doubt on the supposed preponderance of a selective premium for moderately high leafing intensities. Whitman and Aarssen (2010) considered this issue, focusing on the fact that leaf laminas have gradually evolved from tiny epidermal outgrowths to larger leaf surfaces. At a given point, the evolution of increasingly higher leaf sizes would have been compromised by the negative consequences of continued reductions in leafing intensity and in numbers of axillary meristems. This does not look like an argument granting direct adaptive premiums to leafing intensity, but one ascribing it the role of a constraint for the evolution of ever increasing leaf sizes. This is certainly a different view. Therefore, even if the trade-off between leaf size and number is a sound empirical pattern, the leafing intensity premium hypothesis may not be the only plausible explanation to account for this correlation. The above criticisms do not invalidate Aarssen's idea at all, because both can be addressed in empirical ways.

Finally, we should not forget that the evolution of phenotypes is necessarily multifaceted. Natural selection favouring high leafing intensity may have caused concomitant increases in leaf outline complexity as a means to reduce leaf size. This might be one of the forces promoting the evolution of compound leaves. However, there are others- equally plausible and by no means exclusive-which have to be considered jointly. Compound leaves provide a number of physiological and mechanical direct advantages: lower drag to intense winds, or more proficient heat dissipation abilities, for examples (Vogel 1989, Niinemets 1998). Also, rachises are cheaper to build than stems, which may serve specialists in vertical growth to achieve a sufficient degree of lateral leaf display without compromising strong apical dominance (Givnish 1978). Other mechanisms are listed in Aarssen (2012) and Warman et al. (2011). Empirical efforts to test these ideas have not been very numerous, so it may seem logical that, at this stage, they have enjoyed little empirical support: more data are needed. In any case, adaptive value of the compound leaf, in itself rather than as a mere correlate of traits such as leafing intensity, should not be discarded.

In conclusion, it is an excellent way forward to devote more attention to the ecological and evolutionary consequences of plant morphological variation, in general. Aarssen's (2012) proposal is a stimulating idea in this regard. My feeling is that this area is perhaps at too verbal a stage. Think of the excellent and thorough move that research on leaf economic traits has experienced in the latest years. Seminal ideas with modest empirical backing were proposed in the 1970s and 1980s. This was followed by a massive advent of observational and experimental data. The extraordinary impact of Wright et al. (2004) is an illustrative example of this. Together, ideas plus empirical data have produced a reasonable degree of understanding of how economic leaf traits relate with each other, with other plant traits, and with the environment (perhaps with too marginal an interest on micro-evolutionary mechanisms, but see Donovan et al. (2011)). A similar move regarding traits such as leaf outline complexity would surely help us understand key aspects of the evolutionary ecology of plants. Let's test Aarssen's idea (and others')!

\section{References}

Aarssen, L.W. 2012. Reducing size to increase number: a hypothesis for compound leaves. Ideas in Ecology and Evolution 5: 1-5. CrossRef

Bell, A. 1991. Plant form an illustrated guide to flowering plant morphology. Oxford: Oxford University Press.

Champagne, C. and N. Sinha. 2004. Compound leaves: Equal to the sum of their parts? Development 131: 4401-4412. CrossRef

Champagne, C.E., Goliber, T.E., Wojciechowski, M.F., Mei, R.W., Townsley, B.T., Wang, K., et al. 2007. Compound leaf development and evolution in the legumes. Plant Cell 19: 3369-3378. CrossRef

Cronquist, A. 1988. The Evolution and Classification of Flowering Plants. 2nd edition. The New York Botanical Garden, New York, USA.

Donovan, L.A., Maherali, H., Caruso, C.M., Huber, H. and H. de Kroon. 2011. The evolution of the worldwide leaf economics spectrum. Trends in Ecology and Evolution 26: 88-95. CrossRef

Efroni, I., Eshed, Y. and E. Lifschitz. 2010. Morphogenesis of simple and compound leaves: A critical review. Plant Cell 22: 1019-1032. CrossRef

Givnish, T.J. 1978. On the adaptive significance of compound leaves, with special reference to tropical trees. Pages 352-380 in Tomlinson, P.B. and M.H. 
Zimmermann, editors. Tropical trees as living systems. Cambridge University Press, Cambridge, United Kingdom.

Kaplan, D.R. 2001. Fundamental concepts of leaf morphology and morphogenesis: A contribution to the interpretation of molecular genetic mutants. International Journal of Plant Science 162: 465-474. CrossRef

Kleiman, D. and L.W. Aarssen. 2007. The leaf size/ number trade-off in trees. Journal of Ecology 95: 376-382. CrossRef

Milla, R. 2009. The leafing intensity premium hypothesis tested across clades, growth forms and altitudes. Journal of Ecology 97: 972-983. CrossRef

Niinemets, Ü. 1998. Are compound-leaved woody species inherently shade-intolerant? An analysis of species ecological requirements and foliar support costs. Plant Ecology 134: 1-11. CrossRef
Vogel, S. 1989. Drag and reconfiguration of broad leaves in high winds. Journal of Experimental Botany 40: 941-948. CrossRef

Warman, L., Moles, A.T. and W. Edwards. 2011. Not so simple after all: searching for ecological advantages of compound leaves. Oikos 120: 813-821. CrossRef

Whitman, T. and L.W. Aarssen. 2010. The leaf size/ number trade-off in herbaceous angiosperms. Journal of Plant Ecology 3: 49-58. CrossRef

Wright, I. J., Reich, P. B., Westoby, M., Ackerly, D. D., Baruch, Z., Bongers, F. et al. 2004. The world-wide leaf economics spectrum. Nature 428: 821-827. CrossRef 